\title{
Coexistence of granuloma annulare and chronic spontaneous urticaria*
}

\author{
Ilteris Oguz Topal ${ }^{1}$ \\ Pinar Ozay Nayir ${ }^{2}$ \\ Tulin Yuksel ${ }^{1}$
}

\author{
Sule Gungor ${ }^{1}$ \\ Emek Kocaturk ${ }^{1}$
}

To the Editor,

Granuloma annulare (GA) is frequently associated with diabetes mellitus, malignant diseases and infectious diseases. ${ }^{1} \mathrm{~A}$ recent study has shown that GA may be observed concurrently with autoimmune disease, including systemic sclerosis and dermatomyositis. ${ }^{2}$ Herein, we describe a patient with the rare coexistence of granuloma annulare and chronic spontaneous urticaria.

A 59-year old woman presented with a 5-month history of annular lesions on her right arm at our out-patient clinic. She had been admitted to our department 30 years earlier becauseof pruritic papules and was diagnosed with chronic spontaneous urticaria.

Dermatological examination revealed annular erythematous to violaceous plaques on the right forearm and urticarial papules and plaques on the trunk (Figure 1). Routine laboratory parameters and thyroid antibodies were within the normal ranges. But autologous serum test was positive. Histopathological examination of punch biopsy obtained from annular lesion showed focal degen-

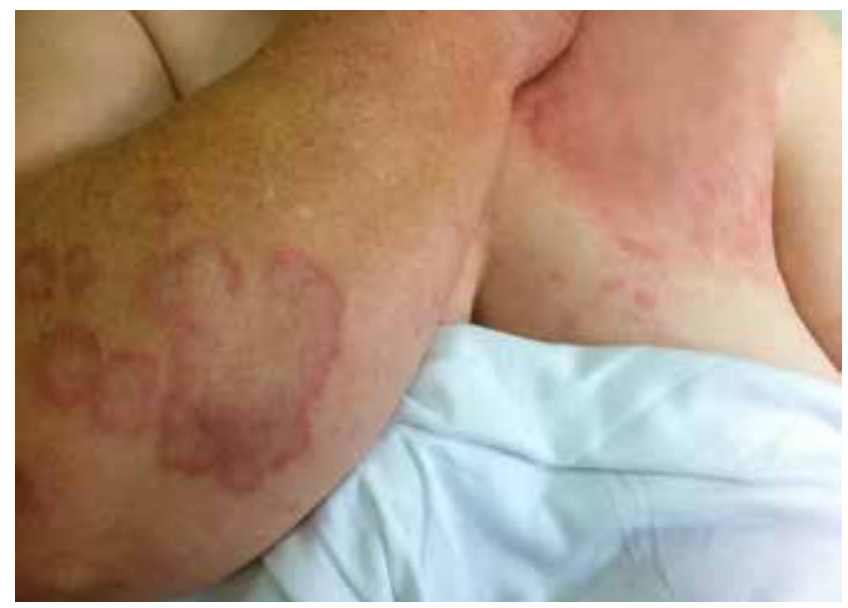

FIGURE 1: Annular erythematous to violaceous plaques on the right forearm and urticarial papules, and plaques on the trunk

\section{Received on 04.09.2015}

Approved by the Advisory Board and accepted for publication on 16.12.2015

* Work performed at the Department of Dermatology, Okmeydani Training and Research Hospital, Istanbul, Turkey.

Financial Support: None.

Conflict of Interest: None.

1 Department of Dermatology.Okmeydani Training and Research Hospital - Istanbul, Turkey.

2 Department of Pathology. Okmeydani Training and Research Hospital - Istanbul, Turkey.

(C2016 by Anais Brasileiros de Dermatologia 


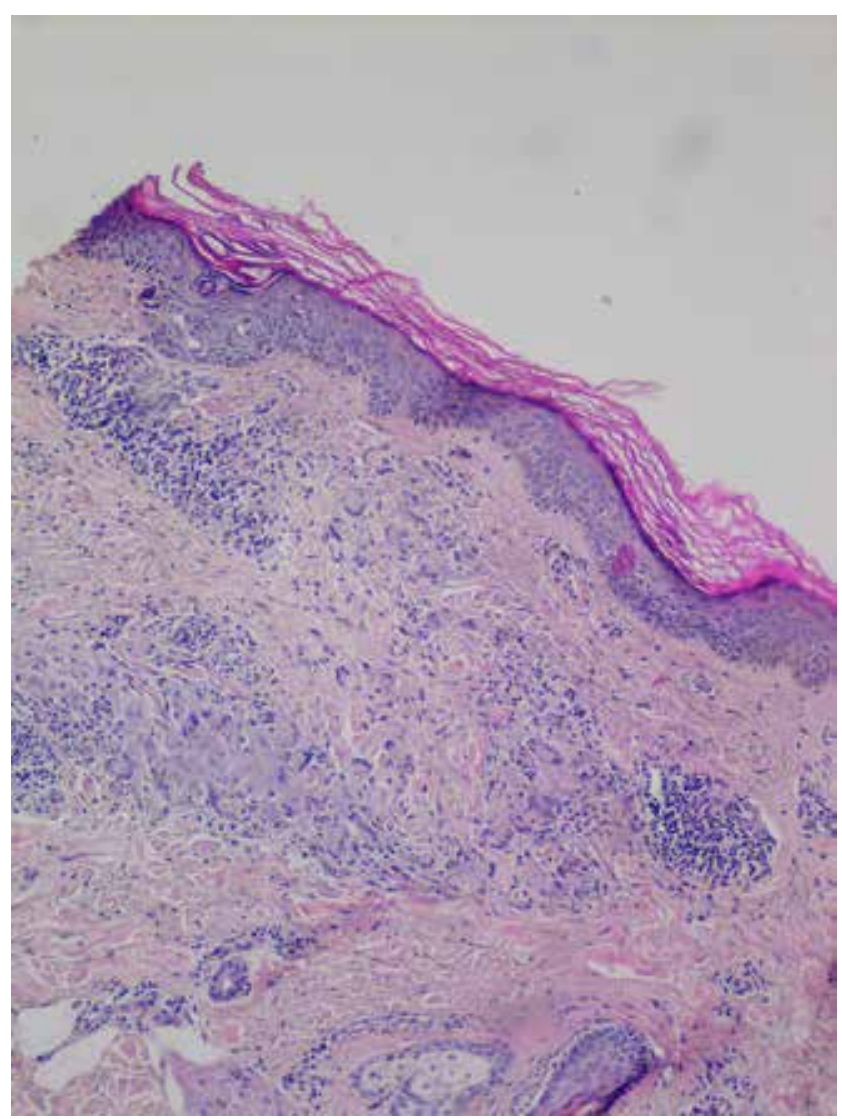

Figure 2: Focal degeneration of collagen bundles surrounded by multinuclear giant cells, histiocytes and lymphocytes in the dermis (HEx40)

eration of collagen bundles surrounded by multinuclear giant cells, histiocytes and lymphocytes in the dermis (Figure 2). These features were consistent with granuloma annulare.

\section{REFERENCES}

1. Thornsberry LA, English JC 3rd. Etiology, diagnosis, and therapeutic management of granuloma annulare: an update. Am J Clin Dermatol. 2013;14:279-90.

2. Sumikawa $\mathrm{Y}$, Ansai $\mathrm{S}$, Kimura $\mathrm{T}$, Nakamura J, Inui $\mathrm{S}$, Katayama I.Interstitial type granuloma annulare associated with Sjögren's syndrome. J Dermatol. 2010;37:493-5.

3. Vázquez-López F, Pereiro M Jr, ManjónHaces JA, González López MA, Soler Sánchez T, FernándezCoto T, T et al. Localized granuloma annulare and autoimmune thyroiditis in adult women: a case-control study. J Am Acad Dermatol. 2003;48:517-20.

4. Soub CRW, Rochael MC, Cuzzi T. Granuloma annulare: tissue distribution of factor Xllla + dermal dendrocytes, thrombomodulin + dermal cells and CD68+ macrophages. An Bras Dermatol. 2003;78:289-98.

5. Nuzzo V, Tauchmanova L, Colasanti P, Zuccoli A, Colao A.Idiopathic chronic urticaria and thyroid autoimmunity: Experience of a single center. Dermato endocrinol. 2011;3:255-8.
Prior reports have noted the occurrence of GA with other diseases such as diabetes mellitus, thyroid disease, hepatitis B, insect bites and lipid abnormalities. ${ }^{1}$ Yet chronic spontaneous urticaria has not been reported. A case-control study showed that frequency of autoimmune thyroiditis increased significantly among adult women with localized granuloma annulare. ${ }^{3}$ However, we did not find autoimmune thyroiditis in our patient.

The cause of GA remains unclear. But there is some evidence suggesting it is an immunologic disease. Various studies have shown that humoral and delayed-type hypersensitivity reaction may be involved in the disease's pathogenesis. ${ }^{1,4}$

Chronic spontaneous urticaria is defined as recurrent episodes of hives with erythema and pruritus occurring over a period of 6 weeks or longer. CSU may have anautoimmune basis and 5-69 $\%$ of patients have autoantibodies to high affinity receptor for Ig E (anti-FceRI) on mast cells and basophils.These antibodies may be pathogenetic upon the onset of CSU. ${ }^{5}$

Immunological changes may occur in both diseases; however, GA and CSU do not usually appear concurrently. As this is the first reported case that we know of it in the literature.

Conclusion: GA may appear concurrently with CSU. The cause for this association is unknown but it seems to be associated with immunogenetic predisposition and autoimmune physiopathologic mechanisms.]

\author{
MAILING ADDRESS: \\ Ilteris Oguz Topal \\ Department of Dermatology \\ Okmeydani Training and Research Hospital, 1233 \\ Istanbul, Turkey \\ E-mail:drilteris@yahoo.com
}

How to cite this article: Topal IO, Gungor S, Nayır PO, Kocaturk E, Yuksel T. Coexistence of granuloma annulare and chronic spontaneous urticaria. An Bras Dermatol. 2016:91(4):552-3. 